\title{
Between Punishment and Care: Autonomous Offenders Who Commit Crimes Under the Influence of Mental Disorder
}

\author{
Thomas Hartvigsson ${ }^{1,2}$ (iD
}

Accepted: 16 July 2021 / Published online: 27 July 2021

(c) The Author(s) 2021

\begin{abstract}
The aim of this paper is to present a solution to a problem that arises from the fact that people who commit crimes under the influence of serious mental disorders may still have a capacity to refuse treatment. Several ethicists have argued that the present legislation concerning involuntary treatment of people with mental disorder is discriminatory and should change to the effect that psychiatric patients can refuse care on the same grounds as patients in somatic care. However, people with mental disorders who have committed crimes and been exempted from criminal responsibility would then fall outside the scope of criminal justice as well as that of the psychiatric institutions if they were to refuse care. In this paper, I present and develop a solution to how society should deal with this group of people, called Advance criminal responsibility. The basic idea being that if a person with a potentially responsibility exempting psychiatric condition refuses care, that person is responsible for any future criminal acts which are due to the mental disorder.
\end{abstract}

Keywords Autonomy $\cdot$ Criminal responsibility $\cdot$ Mental disorder $\cdot$ Involuntary treatment $\cdot$ Insanity defence $\cdot$ Decision-making capacity

\section{Introduction}

The aim of this paper is to present a solution to a problem that arises in the situation when people who commit crimes under the influence of serious mental disorders have the capacity to refuse treatment. Presently, if a person commits a crime under the influence of a mental disorder that person can, in most jurisdictions, be

Thomas Hartvigsson

thomas.hartvigsson@gmail.com

1 School of Philosophy and Art History, University of Essex, Colchester, UK

2 Department of Philosophy, Linguistics and Theory of Science, and the Centre for Ethics, Law and Mental Health (CELAM), University of Gothenburg, Box 200, 40530 Gothenburg, Sweden 
exempted from criminal responsibility on the grounds of legal insanity. In such cases, the excused person will likely be subjected to involuntary psychiatric treatment. The consequence may thus be that, while one and the same person according to criminal law goes free from incarceration, they will be deprived of their liberty in accordance with mental health (administrative) law.

Over the last twenty years, ethicists (e.g., Doyal and Sheather 2005; Richardson 2002; Sjöstrand and Helgesson 2008; Szmukler 2017; Szmukler and Holloway 2000; Tännsjö 1999) have argued that the legislation regulating the involuntary treatment of people who suffer from mental disorders is discriminatory. The principles generally applied to involuntary psychiatric care deviate substantially from well-established and commonly accepted ethical principles. If the critics are right, some people with mental disorders are currently, unjustifiably, being subject to involuntary treatment.

If the legislation regarding involuntary treatment of people with mental disorders were to change in accordance with the critics' suggestion, we could, as I will discuss in further detail below, face a situation in which an offender who has committed a crime under the influence of a serious mental disorder is exempted from criminal punishment but has a right to refuse care. Such an offender would thus not face any further consequences for their actions and may continue to pose a threat to other people.

The problem just outlined stems from a combination of the following three propositions:

1. Some people who commit crimes under the influence of a mental disorder should be exempt from criminal responsibility.

2. Some people suffering from a mental disorder have a right to refuse psychiatric treatment.

3. Some people suffering from a mental disorder pose a threat to other people.

The first two propositions are underpinned by ethical principles regulating how people with mental disorders should be treated by the health care and criminal justice institutions respectively. I will argue that the ethical principles underlying both 1 and 2 are sound but become problematic in the case of potentially dangerous people (proposition 3). I will propose a re-examination of these principles, particularly the ones pertaining to criminal responsibility; a re-examination which will show us a way out of this dilemma. The solution I am proposing will be referred to as Advance criminal responsibility. This special version of criminal responsibility entails that if a person suffers from a condition that might undermine criminal responsibility but has a right to refuse care that would mitigate the condition and uses that right, that person becomes criminally responsible for any criminal acts conducted at a later point due to their (previous) refusal of care. This suggestion is dependent on society providing adequate care and support for all people who suffer from such mental disorders. Further, it carries the implication that an offender without a previous history of mental disorder who subsequently has had no opportunity to refuse or consent to care, but who commits a 
crime under the influence of that disorder, will continue to be exempt from criminal responsibility.

Offenders suffering from mental disorders exist at the intersection of two institutions: that of criminal justice and that of health care. A discussion of how this particular group of offenders ought to be treated needs to involve an examination of the ethical principles guiding both institutions, especially the ones pertaining to the conditions regulating the rights of these institutions to deprive people of their liberty. These ethical principles also justify the first two propositions of the problem described above.

I will address each of the ethical principles in turn: in section two, I describe two versions of the insanity defence and discuss how it is justified in the light of the major normative theories of criminal punishment. In the third section, I discuss the standard legal arrangement concerning the involuntary treatment of people with mental disorders and how it ought to change. In the fourth section, I discuss the group of offenders that suffer from mental disorders and pose a threat to other people as well as suggestions discussed by critics of the present-day order. Finally, in the fifth section, I present the Advance criminal responsibility model and defend it.

\section{Criminal Responsibility and the Insanity Defence}

Most jurisdictions include some form of exemption from criminal responsibility for people suffering from mental disorders (Simon and Ahn-Redding 2008). The precise conditions for such exemptions vary between jurisdictions and the discussion here will only focus on two of them. In its most common version, the exemption from criminal responsibility focuses on the person's knowledge of the act. Roughly, if a person as a consequence of a serious mental condition is judged to lack the ability to appreciate the nature of the act (or that it is wrong) then that person is to be exempt from criminal responsibility. ${ }^{1}$

By criminal responsibility I refer to an institutional concept of responsibility. That is, a person is criminally responsible if the criminal justice institution, in a specific jurisdiction, considers that person an appropriate target of criminal sanctions. This can be contrasted with the notion of moral responsibility, a preinstitutional concept that, according to most theories of criminal punishment, should inform what falls under the concept of criminal responsibility.

The most well-known and discussed version of the insanity defence is the M'Naghten rule. This rule is named after Daniel M'Naghten who murdered Edward Drummond in the belief that he was Robert Peel, the British prime minister of the time. M'Naghten suffered from the delusion that Prime Minister Peel was part of a

\footnotetext{
1 It is notable that even a country like Sweden, which does not exempt people suffering from mental disorders from criminal responsibility, treats this group of offenders differently. If someone is found to have committed a crime under the influence of a serious mental disorder, then such a person may not be sentenced to prison but may instead be sentenced to forensic psychiatric care. In the Swedish system, the offender is thus not exempted from criminal responsibility but from a prison sanction (Dahlin et al. 2009).
} 
conspiracy aimed at him. M'Naghten was later freed from criminal responsibility on the grounds of insanity. This ruling later led to the formulation of the M'Naghten rule by the House of Lords. According to this rule a person is not responsible for having committed a criminal act if "at the time of committing of the act, the party accused was labouring under such a defect of reason, from disease of the mind as not to know the nature and quality of the act he was doing: or, if he did know 'it', that he did not know he was doing what was wrong" (M'Naghten's case 1843).

In some versions of the legal insanity rules, volitional control also plays a role. As an example, the Model Penal Code, used in several states in the USA, states that a person is exempt from criminal responsibility "if at the time of such conduct as a result of mental disease or defect he lacks substantial capacity either to appreciate the criminality (wrongfulness) of his conduct or to conform his conduct to the requirements of the law" (Model Penal Code and Commentaries 1985).

\subsection{The Normative Basis of the Insanity Defence}

The basis of the legal insanity defence is the idea that only those who are morally responsible for a crime - those who are guilty of it-deserve punishment. This principle is a cornerstone of the criminal justice system and is usually linked to the theory of retributivism (Duus-Otterström 2007). Retributivism exists in many varieties, but at the heart of all retributive theories lies the idea that an offender deserves to be punished in proportion to the wrongfulness of the act. This wrongfulness of the act is, in turn, understood in terms of the severity of the deed and the degree to which the offender is morally responsible for the crime (Walen 2014).

Other theories, such as communicative theories (e.g. Duff 2001), share the idea that criminal responsibility should be modelled on moral responsibility. This can be contrasted with consequentialist theories such as the general deterrence theory, which states that a person should be considered criminally responsible if doing so contributes to fewer crimes being committed. The notion of criminal responsibility here is derived not from beliefs about moral responsibility but from other ethical considerations. However, advocates of the general deterrence theory usually argue that the criminal attributions of this theory would approximate those of a retributive theory (e.g. Clark 1997; Hart 2008; Rawls 1955). ${ }^{2}$ The same pattern usually mirrors other consequentialist theories of punishment: if only for pragmatic reasons, they allow the inclusion of some variant of the basic idea that only those guilty of a crime should be subjected to criminal punishment. This means that consequentialist theories, too, support having some variant of an insanity defence.

\footnotetext{
2 There are also other theories, such as negative retributivism, for which the notion of criminal responsibility is the result of both moral responsibility and other considerations. For example, Tadros (2011) has argued in favour of a theory according to which society is permitted to punish someone who is morally responsible for having committed a crime but should only do so if such a punishment contributes to preventing further crimes.
} 


\section{Involuntary Treatment of People with Mental Disorders}

Most countries permit, under certain circumstances, people suffering from mental disorders to be subjected to involuntary psychiatric care. In a review of legislation in the EU member states concerning involuntary treatment and placement, the European Union Agency for Fundamental Rights (FRA) found that involuntary psychiatric care was allowed, although the specific conditions varied: all countries required the presence of a mental disorder and almost all countries required the person suffering from a mental disorder to pose a threat either to themselves or to others (FRA 2012; cf. Dressing and Salize 2004).

The legal rules of the EU member states adhere to a greater or lesser extent to recommendations made by the Council of Europe (FRA 2012). According to these recommendations, the legislation for the involuntary treatment of people with mental disorders should meet four criteria: the person should suffer from a mental disorder; the person should pose a threat to himself or others; no appropriate, less restrictive alternative is available; and the opinion of the person has been taken into account. For involuntary placement, there is an additional criterion that the placement should have a therapeutic purpose (Council of Europe 2004).

According to the recommendation, the involuntary treatment of people with mental disorders applies to those.

i. who have the capacity to consent ${ }^{3}$ and are refusing the placement or treatment concerned; or

ii. who do not have the capacity to consent and are objecting to the placement or treatment concerned. (Council of Europe 2004, article 16)

Article 16 is found in section III of the recommendation, which is concerned with involuntary psychiatric treatment and placement. This section constitutes an exception to the recommendation's general rule that, if they have the capacity to consent, care should only be given to people with their consent, regardless of whether they have a mental disorder or not. If a person who suffers from a mental disorder does not have the capacity to consent then care should only be given "with the authorization of a representative, authority, person or body provided for by the law" (Council of Europe 2004, article 12). The Council of Europe's recommendation thus makes a distinction between the right of people with mental disorders to refuse care for their mental disorder and their right to refuse care for other conditions.

The Council of Europe's recommendation and European Convention on Human Rights and Biomedicine (ECHRB) permit involuntary treatment for mental disorders whereas they do not permit involuntary treatment for somatic care. Neither document provides reasoning for why psychiatric care should be treated differently and as such the exception constitutes a violation of article 3 in the same

\footnotetext{
3 In its Explanatory Memorandum, the Council of Europe (2004) states that they use the term capacity to consent in the same way as the ECHRB (1997) and that having the capacity to consent entails the capacity to refuse treatment.
} 
recommendation, which states that "[a]ny form of discrimination on grounds of mental disorder should be prohibited" (Council of Europe 2004, article 3).

Several ethicists (e.g. Doyal and Sheather 2005; Richardson 2002; Sjöstrand and Helgesson 2008; Szmukler 2017; Szmukler and Holloway 2000; Tännsjö 1999) ${ }^{4}$ have drawn attention to this, in their view, unjustified discrepancy. The discrepancy can be described as a health care ethical objection to any act of involuntary treatment of patients with the capacity to consent. But the regulatory framework for involuntary psychiatric treatment may also be rejected on legal grounds. Due to the internal inconsistency of this framework, the space created for the legal involuntary treatment of psychiatric patients with capacity to consent becomes a case of arbitrary deprivation of liberty. The discriminatory treatment of people with mental disorders is also explicitly addressed by the United Nations in its:

States Parties shall ensure that persons with disabilities, on an equal basis with others ... b) [a]re not deprived of their liberty unlawfully or arbitrarily, and that any deprivation of liberty is in conformity with the law, and that the existence of a disability shall in no case justify a deprivation of liberty. (UN 2006, article 14)

There are two key parts of this article: the first is that the disability in itself is not a ground for depriving people of their liberty and the second is that people with disabilities should be treated on an equal basis with others. Both of these points seem to hold also for mental disorders. In order to justify involuntary psychiatric treatment in a way that escapes the objections, it would seem that we need to demonstrate either that the patient lacks capacity for informed consent, or that there is something else about the patient that may justify involuntary treatment in light of health care ethics and/or the legal framework. In the next section, I will comment on the first issue, and after that comment on the latter possibility.

\subsection{Capacity for Informed Consent and Refusal of Treatment}

Capacity for informed consent is a central concept in health care ethics and marks the line between people who can and cannot permissibly be subjected to involuntary treatment. Mental disorders can undermine a person's capacity to consent but do not necessarily do so. In order to understand the relationship between mental disorders and capacity for consent we need to take a closer look at what is required for a person to have this capacity.

\footnotetext{
4 This critique can also find support in declarations coming from relevant professional organizations. In the declaration of Hawaii, the World Psychiatrist Association states that "[n]o procedure shall be performed nor treatment given against or independent of a patient's own will, unless because of mental illness, the patient cannot form a judgement as to what is in his or her own best interest and without which treatment serious impairment is likely to occur to the patient or others" (WPA 1983, article 5). And in the next article we can read that "[a]s soon as the conditions for compulsory treatment no longer apply, the psychiatrist should release the patient from compulsory nature of the treatment and if further therapy is necessary should obtain voluntary consent." (WPA 1983, article 6).
} 
According to one of the most influential models, the MacArthur Competence (Grisso and Appelbaum 1998), capacity for consent-or in their terminology, competence to consent to treatment-consists of four abilities: understanding, appreciation, reasoning and ability to express choice. Understanding is the ability to comprehend information pertaining to the decision at hand, such as grasping the nature of the illness and treatment options, including non-treatment, and the possible consequences of these. Appreciation is the ability to apply that information to one's own person and circumstances. Reasoning is the ability to use that information in combination with one's preferences to form a decision. The ability to express a choice is precisely that, the ability to communicate the decision made.

Mental disorders can undermine all these abilities but the mere presence of mental disorder does not by default undermine any of them, or at least does not undermine them to a degree that deprives a person of the capacity to consent. One example of how a mental disorder can undermine one of the crucial abilities can be found in cases of anorexia nervosa. This disorder is characterized by the patient being severely underweight and suffering from a fear of gaining weight. Some people with anorexia suffer from a delusion-like belief that they are overweight. It is possible for a patient with anorexia to have extensive knowledge about nutrition and weight gain and loss as well as of general facts about weight in relation to the population at large. Yet they may fail to apply this information to their own situation or have an irrefutable belief that their general knowledge does not apply to their own case. Such a patient would fail to meet the appreciation condition.

The MacArthur competence can be compared with the conditions for mental capacity in the Mental Capacity Act 2005 (MCA) that applies in England and Wales. According to this act.

A person is unable to make a decision for himself if he is unable

a. to understand the information relevant to the decision,

b. to retain that information,

c. to use or weigh that information as part of the process of making the decision, or

d. to communicate his decision (whether by talking, using sign language or any other means).

(Department of Health 2005: 2)

There are some differences between the two models, ${ }^{5}$ but it is the common features that are of importance here. First, capacity to consent is in both models tied to one

\footnotetext{
5 The difference between the two models is their respective second condition. MacArthur competence requires a patient to be able to apply relevant information to their particular situation (appreciation) whereas the MCA explicitly demands the information to be "retained". The MCA does not specify what retain means but notes that a person should not be regarded as lacking capacity if they can only retain information for short period of time. The appreciation aspect of the MacArthur competence can arguably be included in criterion (c) of the MCA model, while criterion (b) of this model is likely to be included in all the abilities of the MacArthur competence abilities except ability to express choice.
} 
specific decision. It is possible to have the capacity to make one particular decision but lack the capacity to make another. Likewise, it is possible to have the capacity to make a particular decision at one specific time but not another. The patient with anorexia described above could very well have the ability to appreciate information related to a decision regarding the removal of a tumour in her hand. Likewise, this patient could gain the ability to appreciate information related to the treatment of anorexia after having received therapy. Most importantly, due to this decision relativity, the fact that an offender has been declared "not guilty by reason of insanity" is no reason in itself to assume that this person lacks the capacity to consent to psychiatric care or to specific treatments within such care.

Second, none of the models require any particular cause for lack of capacity. Lack of capacity can be due to mental disorder, cognitive impairment, emotional distress or a physical injury (such as blood loss, a hit to the head, or any other cause that diminishes any of the required abilities).

Yet, the idea of using capacity to consent as a demarcation for when it is permissible to subject a patient to involuntary treatment has been met with criticism, most notably from the UN Committee on the Convention on the Rights of Persons with Disabilities (CRPD). They argue that such tests are "discriminatorily applied to people with disabilities" and that they presume "to be able to accurately assess the inner-workings of the human mind". The result of such tests is then used to deprive people of "a core human right - the right to equal recognition before the law" (Committee on CRPD 2014: 4).

The committee's first argument that capacity conditions are discriminatory does not seem to be an argument against capacity conditions in principle or the capacity models discussed here. Rather it seems to be an argument against existing assessment practices. The committee's argument is best interpreted as an argument similar to the previously mentioned ethicists' criticism based on the regulatory discrepancy between the room for involuntary treatment in psychiatry and somatic health care. But to make that point, we need to assume the presence of an ethical standard of informed consent, which in turn requires the notion of capacity for consent and methods to assess such capacity.

The committee's second argument seems far more problematic as we make assessments of each other's mental states all the time and psychologists and other researchers have developed sophisticated methods for understanding how our psychology works. The fact that capacity conditions may require us to assess the mental states of other people is no argument against this, albeit that it is a reason to be rigorous when making assessments. ${ }^{6}$

\footnotetext{
${ }^{6}$ For a more thorough critique of the Committee's comment on the CRPD see Martin et al. (2014).
} 


\section{Dangerousness as a Reason to Limit the Right to Refuse Treatment}

One reason for the involuntary psychiatric detention of psychiatric patients in general, and of offenders who have been exempted from criminal responsibility due to a successful insanity defence in particular, is their alleged dangerousness. Could the proposed change in legislation, that people suffering from a mental disorder should have a right to refuse care if they have capacity, deal with this alleged dangerousness?

First, it should be recognized that the group under discussion is small. It is very rare that people who suffer from mental disorders are acquitted of criminal responsibility. A review found that during 2002-2011 a total of 223 people in England and Wales were exempted from criminal responsibility on the grounds of insanity (Mackay 2012). A recent meta-analysis on studies made in the US of people freed from criminal responsibility by reason of insanity found that, even though the included studies showed some variation, on average the insanity defence succeeded in $25 \%$ of the rare instances when it was invoked. The metaanalysis further showed that it was primarily disorders on the psychosis spectrum that lead to acquittal on grounds of insanity (Kois and Chauhan 2018). The crimes committed by offenders in England and Wales were predominantly violent crimes, such as assault, attempted murder, and arson. Successful murders only made up around a tenth of all attempts (Mackay 2012).

It might be argued that a person who suffers from a mental disorder that is severe enough to undermine criminal responsibility cannot at the same time have the capacity to refuse treatment. However, as argued in the previous section, this assumption cannot be substantiated on a conceptual level, but it may of course be the case that, statistically, the two phenomena tend to come together. To my knowledge, no studies have been made of offenders exempt from criminal responsibility due to the influence of a mental disorder to see if they also have capacity to refuse treatment. However, some studies have been made concerning capacity to consent or decision-making competence on psychiatric patients. When patients in psychiatric care are compared to patients in somatic care, the rate of patients with the capacity to consent to treatment is higher in somatic care, but in both types of care both patients with and without such capacity can be found (Owen et al. 2013). Mandarelli and colleagues (2014) have examined the decision-making competence of 60 patients in both voluntary and involuntary psychiatric care. They found that competence varied greatly within each group but that the patients in voluntary treatment in general had higher decision-making competence. The differences between the groups were particularly salient with regards to appreciation and reasoning. However, there were patients in the involuntary treatment group who scored high on the different competence abilities. In a study of 338 patients at psychiatric wards, Owen and colleagues (2008) found that approximately $60 \%$ (95\% CI 55-65\%) of the patients lacked decision-making competence. The share of patients who were decision-making competent varied with the diagnosis. People suffering from bipolar affective disorder-mania lacked competence to the highest degree followed by schizophrenia and other psychotic 
disorders. A significantly larger part of patients suffering from depression and bipolar affective disorder-depression were found competent. The conclusions we can draw from these studies is that there are patients in involuntary treatment who meet the requirements for decision-making competence and thus have the capacity to consent.

Even though the same mental disorders that tend to undermine criminal responsibility also tend to undermine capacity to refuse treatment, there will always be room for offenders with mental disorders to have the capacity to refuse treatment. The reason for this is the decision-relative nature of both criminal responsibility and capacity to consent. The decision to commit a crime is different from a decision to refuse or consent to treatment. A person suffering from a compulsive mental disorder might have a perfectly adequate understanding of their condition and as such be able to competently make decisions about a possible treatment. Second, the decision to commit a criminal act is usually taken at another time than the decision to accept or refuse care. A person's mental state may shift over time and, for example, the use of anti-psychotic medicine can re-establish a person's capacity.

\subsection{Previous Suggestions for Preventing Harm From People with Mental Disorders}

A few scholars have addressed the ethical division of labour between criminal justice institutions and health care institutions when it comes to offenders suffering from mental disorders. However, these have suggested and discussed a number of proposals concerning how this group should be handled.

Tännsjö (1999) suggests what he calls a full responsibility model. He argues on consequentialist grounds that no exemption from criminal responsibility should be made for people even where the offence is due to a severe mental disorder. This strategy would nip the problem in its bud. However, as we saw earlier, prominent proponents of consequentialist justifications of the criminal penal system argue that the allocation of criminal responsibility should indeed emulate that of moral responsibility. Tännsjö's suggestion entails a violation of this contention, as it abandons the principle that only people who are guilty of committing a crime should be subject to criminal punishment.

Szmukler (2017), Dawson and Szmukler (2006), Szmukler, Daw and Dawson (2010) has repeatedly argued for what he calls fusion law:

a single, generic law governing treatment without consent that covers all patients, in all specialties, in all settings-medical, surgical, psychiatric, nursing and care homes, or indeed, anywhere in the community. (Szmukler 2017: 86)

According to this proposal, involuntary treatment should only be permissible when the patient does not have capacity to refuse treatment and the treatment is the least restrictive way of promoting the patient's interests. However, Szmukler (2017) also acknowledges that some people who suffer from mental disorder pose a danger to other people. He therefore reluctantly suggests a compromise, that an exception 
should be made for offenders who are found not guilty by reason of insanity and who have capacity to refuse care. Involuntary treatment of this group is, according to the fusion law compromise, permissible if there is an effective treatment available and that the time of the treatment lasts no longer than the prison sentence for the crime they were acquitted from. This solution is obviously unsatisfying as it goes against the principle underlying the fusion law, something that Szmukler also acknowledges. A further downside is that Szmukler's exception does not satisfactorily handle the problem motivating him to sidestep the fusion law as the necessary care might last for a longer time than the relevant prison sentence. Moreover, in some cases there may not exist any remedy but the need to protect the public would still be there.

A third way of dealing with dangerous offenders who suffer from mental disorders could be preventive detention. Versions of this exist in many countries, such as Canada (Department of Public Safety and Emergency Preparedness 2009), Germany (German Criminal Code 1998) and Norway (Straffeloven 2 kap. §39c). The idea underlying the practice of preventive detention is that if a person poses a threat to other people's lives and safety then it is permissible to limit that person's freedom if necessary. A parallel can be made to public health and the practice of putting people who carry dangerous and contagious diseases in quarantine (cf. Douglas 2019). People who carry transmittable diseases might have done nothing wrong but it is still justifiable to isolate them under certain conditions to prevent the spread of the disease. Similarly, it would arguably be justifiable to put certain people in quarantine on the basis of their dangerousness, if the danger is imminent.

In order for preventive detention to be justified we must thus be able to determine how dangerous a person is to other people. Furthermore, we must also decide where to draw the line regarding how dangerous a person must be to become subject to preventive detention. A trade-off has to be made between promoting the value of protecting people from harm and the value attached to the individual's freedom. We can note that in the case of the countries mentioned above at least one crime has to be committed by a person in order for preventive detention to apply.

How the trade-off is made is in part dependent on the degree to which we can actually predict future offences. There are a number of ways in which the risk a person poses to others can be assessed. In addition to unstructured clinical judgments made by a psychiatrist or a psychologist, a number of formal tools have been developed such as HCR-20 and VRAG. A number of other more specific tools targeting specific crimes and populations such as adolescents' proneness to violence or risk for recidivist sexual offences are also being used. Additionally, tools such as the PCL-R that were not originally developed to predict risk are also being used for this purpose. The effectiveness of these tools to predict future criminal and violent activities varies considerably and any such tool may differ in predictive power for different demographic groups (Singh et al. 2011). With these tools it is possible to make better predictions about the likelihood of future violence than mere chance would provide us with (SBU 2005) but they do not tell us how to weigh the opposing values. Especially regarding forensic psychiatric detention, the use of these kinds of risk assessment methods has been heavily criticized on both methodological and ethical grounds (Nilsson et al. 2009). 
One advantage of the basic idea of preventive detention is that it can be applied to all offenders whether they have a mental disorder or not. Only their assessed dangerousness should be used as a ground for detaining them. There are some studies suggesting that mental illness is linked to violence, in particular schizophrenia and bipolar disorder (Arseneault et al. 2000; Elbogen and Johnson 2009; Swanson et al. 1990). However, this link between violence and mental disorder can to a great extent be explained by substance abuse (Elbogen and Johnson 2009; Fazel et al. 2009; Fazel et al. 2010; Steadman et al. 1998; Swanson et al. 1990). Moreover, as many psychiatric diagnoses include the presence of independent risk factors (substance abuse, lack of impulse control and past norm-breaching behaviour, for instance), there is a risk that the recidivism risk of offenders suffering from mental disorders is unduly exaggerated (Nilsson et al. 2009). It might be that future research will show that certain mental disorders increase the probability that a person will engage in violence. In that case, information about the relevant kinds of mental disorders should inform the risk assessment, but it will not provide a reason to treat mentally disordered offenders differently from criminals without such disorders.

Preventive detention is controversial as a means to protect people from harm since it seemingly imposes punitive measures on people in addition to the punishment that has been judged appropriate as a societal response to their crimes. At the same time, some people pose a continuous threat to other people. If preventive detention is used, like in the legislative examples referred to here, the bar for when a person is subject to it will be high and some offenders who suffer from mental disorders will be considered dangerous but still not dangerous enough for preventive detention to be warranted. I do not, here, wish to take a stand on whether or not preventive detention is justified but note that on its own it is unlikely to deal with the perceived danger of offenders with mental disorders, but it can work as a complement to Advance criminal responsibility, which I describe in the next section.

\section{Prior Fault and Advance Criminal Responsibility}

Not only people who suffer from mental disorders can find themselves in a situation in which they are not responsible for their actions. Such circumstances can for example be brought about by temporary confusion, drugs and somatic illness. From the standpoint of the principle that criminal responsibility should emulate moral responsibility, an important distinction in these cases is whether a person has brought about these states or not. This is often expressed in terms of a Prior Fault Rule, which exists in some form in most legal systems. If an offender, who is assessed as being not responsible due to a lack of understanding or control at the time of the crime, knowingly put themselves in this situation, they may in the end be held responsible. In the following I will suggest an extended application of this principle, which I will call Advance criminal responsibility. But first, consider the following two examples.

\section{The Ruthless Criminal}

A person sets out to commit assault. In order to become more violent and less compassionate the person takes Rohypnol in combination with alcohol before 
doing the deed. Rohypnol also has the likely side-effect that the episode will be blurred in the perpetrator's memory which will make a later interrogation harder (Dåderman and Lindberg 1999; Dåderman et al. 2002). This ruthless criminal is, in this case, clearly morally responsible for the ensuing assault, and this assessment seems to be strengthened rather than weakened by the cynical preparations. This is so even if, at the time of the crime, the Rohypnol had rendered the ruthless criminal's mental state such that, had it had not been caused by a prior fault, the perpetrator would not have been responsible.

\section{The Back-Firing Spiked Drink}

In addition to being used as an aggression and callousness enhancer, Rohypnol is also used as a date-rape drug. In addition to causing hazy memories, it can cause a victim to lose the ability to resist what is happening to them (Dåderman and Lindberg 1999; Dåderman et al. 2002). However, in this case the use of Rohypnol backfires and the victim of the date-rape drug suffers a fit of rage and takes on the would-be rapist in a way that amounts to unlawful battery. The victim would probably not be held responsible for their actions when under the influence of Rohypnol since the drug severely diminishes their ability to control their aggressive impulses. Neither are they responsible for having brought themselves into that state, so there is no prior fault. The would-be rape victim would therefore not be morally responsible for the assault.

The situation of the spiked-drink victim is in many ways similar to that of people who commit crimes under the influence of mental disorders (or some other condition that potentially exempts them from criminal responsibility), in that they are not responsible for the mental states that reduce their capacity for responsibility. That a person suffers from a mental disorder is a result of a genetic disposition in conjunction with environmental factors that are to a large part outside the control of the person. However, the actual circumstances in which people with mental disorders commit crimes usually paint a more complex picture. Someone who commits a crime under the influence of a mental disorder is statistically likely to have had previous contact with psychiatric care (Kois and Chauhan 2018). The mental health problems and their nature is thus often known to the offender prior to the crime. This is especially true in cases where a person is re-offending. The idea underlying Advance criminal responsibility is that if a person knowingly enters into a state in which they know that they might pose a threat to other people by virtue of their mental disorder, and acting under the influence of that disorder would exempt that person from criminal responsibility, then the person is responsible for any actions committed under the influence of that mental disorder. A person who has the capacity to refuse care and who is aware of their mental disorder and the associated risks should, according to Advance criminal responsibility, be held responsible for any later crimes that the person commits under its influence. By refusing care they, so to speak, would take on criminal responsibility in advance.

Others (e.g. Law commission 2013; Mitchell 2003) have made a comparison between people with mental disorders who quit their medication (and hence do not follow the treating physician's recommendation) and people who voluntarily get 
intoxicated. They note that people who commit crimes while intoxicated are not exempt from criminal responsibility. Unlike the ruthless criminal in the previous example, people who suffer from mental disorders do not refuse treatment in order to commit crimes but rather in order to achieve some other end, such as avoiding unpleasant and sometimes severe side-effects of medication. Similarly, a person who commits a crime under the influence of a substance may, in contrast to the ruthless criminal, not use this substance in order to commit a crime but rather for some other end, such as enjoying the pleasant effects of the drug.

The fact that a person uses a drug with recreational intent is, however, not a reason to absolve that person from criminal responsibility should they commit a criminal act under its influence. For example, a person taking LSD may do so for the purpose of having a psychedelic experience but may have a bad trip, have terrifying hallucinations and become violent and aggressive. That person would be in an altered state of mind that in other circumstances would exempt the person from criminal responsibility, but it does not do so in this case as they put themselves in the drug-induced state and were aware of the risks associated with drug use. In the same way, a person who suffers from hallucinations and is offered but refuses treatment is responsible for being subject to those hallucinations.

Advance criminal responsibility may, further, be philosophically grounded in the distinction between option luck and brute luck, embraced across many camps in debates on moral responsibility.

Option luck is a matter of how deliberate and calculated gambles turn outwhether someone gains or loses through accepting an isolated risk he or she should have anticipated and might have declined. Brute luck is a matter of how risks fall out that are not in that sense deliberate gambles. (Dworkin 2000: 73)

Ronald Dworkin (2000) uses the example of insurance to explain this distinction. If a house is struck by lightning, this is a matter of bad brute luck. However, before the lightning strikes the house owner has an option whether or not to take out an insurance on the house. When lightning strikes it is good option luck to have taken out an insurance and bad option luck not to have done so. In the case at hand, a genetic disposition for mental disorder is a matter of brute luck, whereas the outcome of the decision to refuse treatment is a matter of option luck. When the patient refuses treatment the person takes a deliberate decision to expose themselves to the risk of committing a crime for which they would not be criminally responsible if that act was just considered in isolation. Consenting to treatment is hence analogous to accepting an insurance against harming the people who would have been harmed by this crime, and insurances can be taken out even if the event it protects against is very unlikely, such as the event of lightning striking the house.

Advance criminal responsibility is the idea that a person takes on criminal responsibility for any later criminal acts done under the influence of a mental disorder when they refuse care (deemed necessary by a physician and/or a court) for their psychiatric problems. This suggestion hinges on two crucial features. First, that people are responsible for refusing care and second that we can pinpoint disorders that, potentially, can exempt someone from responsibility. I will present a sketch of these two features in the next two sections. 


\subsection{Responsibility Conditions and Refusal of Care}

People with mental disorders who commit crimes exist at the intersection of health care and criminal justice institutions, but the specifics of this intersection are dependent on the precise nature of rules and practices pertaining to these institutions. Even though I argue for a principled major change to these, it is still necessary when implementing such a change to pay attention to, and to respect, the legal system and traditions of each individual country. This means that there will, in all likelihood, be differences in how this principled change is implemented and understood. However, there will be several problems, common to all systems, that need to be solved and delimitations that need to be done. I will try and sketch a few suggestions for how some of these problems can be handled while keeping in mind that different jurisdictions will have to meet these challenges in different ways.

The first problem concerns what conditions a person must meet in order to incur Advance criminal responsibility when refusing care. A reasonable suggestion is that the condition for criminal responsibility should be used for this purpose as well. One situation that we want to avoid is when a person has a right to refuse care but does not meet the conditions for criminal responsibility. That these two can come apart is what created the problem in the first place and Advance criminal responsibility is a suggestion to close that gap. It was previously argued that regardless of how the conditions for capacity to consent and the conditions for exempting someone from criminal responsibility are specified there will always be a set of people who will, after committing an unlawful act, fall outside the scope of the criminal justice system as well as that of administrative involuntary treatment. This is due to the fact that a decision to commit a criminal act and a decision to refuse care are two different decisions made at different times. Hence, the assessments of criminal responsibility and involuntary commitment are dependent on different aspects of a person's mental capacities at different times. If someone is to incur Advance criminal responsibility by refusing care, then the conditions for having a right to refuse care need to be identical to, ${ }^{7}$ or more stringent than, the conditions for criminal responsibility.

Starting from the conditions, already presented in this paper, for criminal responsibility-M'Naghten rule and the Model Penal Code — and for capacity to consentMacArthur competence and the MCA - it is important to keep in mind that the concepts at hand are institutional in the sense that they are being interpreted and used within certain institutions. Their meaning is thus, within certain limits, determined by their use in particular cases within their respective institutions. To compare actual usage of the conditions within these domains lies outside the scope of this paper. However, it is possible to examine the conditions and their wording as such.

\footnotetext{
7 This suggestion has been made by Juth and Lorentzon (2010). However, this would require a substantial change in the conditions pertaining to criminal responsibility in most legal systems. Further, this solution requires that there are good, independent arguments for equating the two different sets of conditions. The justification for exempting people with mental disorders from criminal responsibility is that they are not morally responsible for certain acts, while the justification for giving the right to refuse treatment to people with mental disorders who have capacity to consent was to respect their autonomy and not unduly discriminate against them.
} 
There is a considerable overlap in phrases between the conditions for criminal responsibility and the conditions for capacity to consent. Understanding is a part of the M'Naghten rule, Model Penal Code, MacArthur competence and MCA. Appreciation, which is usually considered to be a stronger version of understanding, appears in both the Model Penal Code and MacArthur Competence.

Despite these similarities there are some differences between these domains. Both of the conditions for capacity to consent demand that a person needs to have the capacity for reasoning. This is not part of any condition for criminal responsibility (i.e. lack of capacity for reasoning is not in itself a ground for exempting a person from criminal responsibility in any rule). The conditions for capacity to consent are more stringent by virtue of this demand.

Both models for criminal responsibility refer to knowledge of right and wrong and might therefore seem more stringent than the two models for capacity to consent. However, there are two problems with stating that conditions for criminal responsibility are more demanding because of this condition. First, capacity to consent assumes that all available alternatives, i.e. treatment and refusals, are legal options. The requirement that a person has a grasp of right and wrong in the criminal responsibility sense is irrelevant for capacity to consent. Second, in order to have capacity to consent a patient needs to have an understanding of the nature of their illness and the possible consequences of both treatment and refusal. Understanding that one's mental disorder can put a person in a situation in which horrible deeds are done is one important consequence. Moreover, since mental disorders can contribute to the production of a number of different crimes it is necessary that a person, to have capacity to consent, understands this and also understands the nature of these crimes. Since this is complex information it will raise the bar for when a person is considered to have capacity to consent. This, in turn, will decrease the number of people who meet this threshold. Furthermore, the risk and nature of possible future crimes cannot fully be understood and definitely not appreciated unless the wrongness of criminal acts are taken into account. ${ }^{8}$

If we compare the conditions for (exempting someone from) criminal responsibility with the conditions for capacity to consent we see that a person might fall between the cracks if the Model Penal Code is combined with the Mental Capacity Act 2005. The Model Penal Code requires that the offender can appreciate the wrongness of their act whereas the MCA only requires understanding. It is possible to consider appreciation to be an aspect of understanding but if this is not the case then the Model Penal Code is more stringent in this respect than the MCA and it is thus possible that someone might have capacity to consent but not be criminally responsible for their decision.

\footnotetext{
8 The notion of knowing that something is wrong is ambiguous as it can refer to law, personal morality, public morality or the moral truth (Sinnott-Armstrong and Levy 2011). I cannot here go into the implications of these different interpretations for the question at hand. Only the last of these interpretations, which is also the most controversial interpretation, is the hardest to reconcile when equating criminal responsibility and capacity to consent.
} 
It is impossible to settle the issue on what the precise conditions for criminal responsibility and capacity to consent should be at this stage. The aim of the previous discussion has been to show that it is at least possible to construe conditions according to which capacity to consent entails criminal responsibility. When implementing Advance criminal responsibility, attention needs to be paid to how these conditions relate to each other.

Given that we have been able to establish conditions for criminal responsibility and capacity to consent, someone needs to assess whether the person in question meets these conditions. Advance criminal responsibility should build upon present systems and be adapted to these. The decision that a person lacks capacity to consent, or lacks criminal responsibility, are legal decisions. The latter is commonly decided by a criminal court, which is informed by a psychiatric evaluation. The former can be decided by a special judge, a court or a health care professional depending on the legislation and situation. Since the assessment of a person's capacity is to be made in relation to a care situation, it seems appropriate that those who presently make decisions regarding involuntary treatment also assess capacity for criminal responsibility. Unlike certain acute medical situations that can arise regarding involuntary care, ${ }^{9}$ assessments of Advance criminal responsibility will not be done under the same time pressure and it might thus be advisable to have a psychiatrist making an evaluation that then informs the decision of whether a person has capacity to consent.

\subsection{Future Offences and Mental Disorder}

The second key feature of Advance criminal responsibility is that we must be able to pinpoint which psychiatric conditions might exempt a person from criminal responsibility. At first glance, this seems fairly easy. It can be regarded as an empirical question. What we need to do is study cases in which people have been exempted from criminal responsibility and see what conditions these people suffered from at the time of the crime. Studies have found that the vast majority of people who are exempted from criminal responsibility suffer from some kind of psychotic or mood disorder (Crocker et al. 2015; Mackay and Kearns 1999; Mackay et al. 2006). However, there are also some conditions that occur in rare cases, such as PTSD (Mackay and Kearns 1999). If a person suffers from one of the conditions that may exempt them from criminal responsibility, and they refuse care for that condition, then that condition will not be a ground to exempt them from responsibility in the future.

However, there are two main problems with this approach. The first problem is that several people who commit crimes under the influence of mental disorders suffer from multiple mental disorders, such as a combination of a substance abuse disorder and a psychotic disorder or the latter in combination with a personality disorder (Crocker et al. 2015). The second problem is that a person's diagnosis might change over time.

\footnotetext{
9 An extreme acute situation could involve a patient in an uncontrollable fit of rage at the emergency department.
} 
If a person commits a crime under the influence of a mental disorder and is diagnosed with comorbid conditions, one of those diagnoses will be considered primary. In that case, one can assume that it is also this condition that is the main cause for the criminal act. Another approach could be a close examination of what role different psychiatric conditions have, when an offender commits a crime under the influence of a mental disorder. Even though this is important from a legal standpoint it might be challenging to do in practice and it might also be difficult from a theoretical point of view since several conditions can contribute to a criminal act while only one of them is relevant from an exempting point of view. What one would need to do is to isolate the exempting condition from a cluster of psychological features that together led to the crime. An approach that seems promising for dealing with this problem is to view mental disorders as part of a causal condition for (criminal) acts and explore if such an isolation is possible through the use of available causal theories. $^{10}$

The second problem is that diagnoses may vary over time and a person might receive a different diagnosis from different psychiatrists. This poses a problem for Advance criminal responsibility since it hinges on the stability of a person's mental condition over time. If a person refuses treatment for one set of psychiatric diagnoses and then commits a crime and is determined by the forensic psychiatrist to suffer from a another set of psychiatric diagnoses, does the first refusal still transfer criminal responsibility? However, another strategy is possible. Instead of focusing on diagnoses one could focus on symptoms and functional impairments. These might be more stable over time and the differences in diagnoses can possibly be explained by different professionals relating these symptoms and functional impairments to different diagnoses (King and May 2018). This suggestion is also more in line with the general approach of focusing less on diagnoses and more on concrete problems.

Further research is necessary to determine which of these two strategies offers the most promising way of meeting this challenge. However, whichever of these strategies one chooses, two key aspects seem to be the same. First, regardless of whether one chooses a diagnosis-based or a symptom-based strategy, the assessments of Advance criminal responsibility will be sensitive to the development of practice regarding assessments of criminal responsibility. New rulings might entail that new disorders, symptoms or combinations thereof may be grounds for exempting a person from criminal responsibility. New rulings may also exclude disorders, symptoms or combinations thereof from exempting a person from criminal responsibility. Thus, there needs to be a feedback mechanism from the criminal courts to the institutions that make assessments of Advance criminal responsibility.

Second, since both diagnoses and symptoms can change over time, Advance criminal responsibility may need to be reassessed as the clinical status of the

\footnotetext{
$\overline{10}$ This has been suggested with regards to INUS-conditions (Anckarsäter et al. 2009): the presence of mental disorder would in that case, together with other factors be sufficient to make a person commit a crime. The mental illness would be a necessary part of a specific set of conditions which together brings about the crime. Other approaches, such as the explanation hypothesis, are also possible (Björnsson and Persson 2012).
} 
person changes. This would offer an individualized approach to reassessment. However, it should also be possible for individuals to change their minds. That a person has refused treatment at one point should not make the person Advance criminal responsible if they later consent to treatment. In that case they should be absolved from Advance criminal responsibility from the point of treatment. Likewise, a person who first consents to treatment but later decides to stop the treatment would then incur Advance criminal responsibility as they no longer are being treated for their disorder.

A further question might be raised concerning the scope of Advance criminal responsibility with respect to different crimes. Once again, this is something that must be decided in dialogue with the practice of the criminal justice institution. It is further an issue that cannot be settled within the scope of this paper. However, I will offer a general approach for how this problem could be dealt with.

In many jurisdictions people with epilepsy are subject to restrictions with respect to driving cars as a seizure would make them lose control over the car and consequently pose a threat to other people. If permitted to drive at all, requirements are made that no symptoms of epilepsy have been present for a number of years. This reasoning is not limited to driving cars but all activities in which losing control of one's body would endanger other people, such as working heavy machinery in the presence of other people.

Mental disorders are different from epilepsy in several aspects, of which two are relevant here. First of all, in epilepsy it is the presence of symptoms that creates a threat to other people. A person with a mental disorder can have symptoms for a long time without posing a threat to other people. Second, epileptic seizures make it impossible for a person to act as this requires control over one's body whereas people with mental disorders can initiate action. M'Naghten for example was motivated by his delusions of a conspiracy against him to seek out and attempt to kill Robert Peel. However, regardless of these differences the common relevant feature of mental disorder and epilepsy is that the person in question is not responsible for what happens. Further, the requirement that people with epilepsy are subject to strict limitations for when they are allowed to drive a car suggests that only a (very) low threshold of posing a threat to others needs to be met.

Further, it does not seem necessary to tie the mental disorder or symptom to a specific future crime. The insanity defence is foremost invoked in relation to violent crimes such as assault, murder, arson and so on. It is, however, impossible to predict in which manner the mental disorder will express itself since that is bound to be influenced by the particular circumstances in which the act is performed. A parallel can here be drawn to people who commit crimes under the influence of drugs. Drugs can induce states that are in many ways similar to symptoms of a mental disorder, such as hallucinations and intense emotional states. That this is rare or can be unpredictable is not a reason to exempt people who commit crimes under the influence of drugs from criminal responsibility. 


\subsection{The Status of Consent and Refusal}

Being faced with the decision to refuse care and incur Advance criminal responsibility or to consent to psychiatric treatment is not a favourable situation. It may even be argued that some patients do not have a genuine choice when offered health care because they cannot afford the treatment. Medical expenses are a problem for many people and in particular for people who commit crimes under the influence of mental disorders as they to a large extent are unemployed and have limited economic means (Kois and Chauhan 2018). Psychiatric treatment therefore needs to be affordable in order for it to be a genuine option. Furthermore, if Advance criminal responsibility is to be successfully implemented, treatment must also be easily available since many people with psychiatric conditions might shy away from other people and, in part due to lack of economic resources, may find accessing appropriate care difficult. Therefore, psychiatric care also needs to be readily accessible.

Even if psychiatric care is available and affordable, the severe side-effects of some psychiatric medications provide good and understandable reasons for why a person would want to refuse care. Neither living with a mental disorder nor living with severe side-effects are appealing options; nevertheless, it is a decision that, in implementing Advance criminal responsibility, has to be made. As it is now, this decision is not in the hands of the patients but in the hands of health care institutions. The proposed reform would mean a significant shift of power from health care institutions to patients. The side-effects of a particular medicine might be unbearable for a patient and because of this they might decide to refuse treatment, knowing that they, in addition to bearing their mental disorder, would incur Advance criminal responsibility. It is a hard choice but at least the choice would be theirs.

\section{Conclusion}

In this paper I have presented and argued in favour of a new approach for society to deal with dangerous people who suffer from mental disorders but who have the capacity to refuse care. The present-day standard regarding the involuntary treatment of people with mental disorders should change so they cohere with the laws regulating somatic care. People who have the capacity to refuse care should have that capacity recognized and respected-regardless of whether they suffer from a mental disorder or not. If such a person suffering from a mental disorder refuses care for that disorder, or social support to manage it, knowing the stakes in terms of the risk of criminal behaviour, then they will, by virtue of the Prior Fault Rule, be responsible for any later act that is brought about by this refusal of care or support. If a person commits a crime during the first outbreak of a sufficiently serious mental disorder then that person should not be held criminally responsible since the criminal justice system should respect its central tenet that only those guilty of committing a crime should be subjected to punishment. 
Funding Open access funding provided by University of Gothenburg. This research was supported by the Swedish Research Council for Health, Working Life and Welfare (FORTE), no. 2018-01409 for the project Development of Evidence Based Practice in Forensic Psychiatry.

Open Access This article is licensed under a Creative Commons Attribution 4.0 International License, which permits use, sharing, adaptation, distribution and reproduction in any medium or format, as long as you give appropriate credit to the original author(s) and the source, provide a link to the Creative Commons licence, and indicate if changes were made. The images or other third party material in this article are included in the article's Creative Commons licence, unless indicated otherwise in a credit line to the material. If material is not included in the article's Creative Commons licence and your intended use is not permitted by statutory regulation or exceeds the permitted use, you will need to obtain permission directly from the copyright holder. To view a copy of this licence, visit http://creativecommons.org/licen ses/by/4.0/.

\section{References}

Anckarsäter, Henrik, Susanna Radovic, Christer Svennerlind, Pontus Höglund and Filip Radovic. 2009. Mental disorder is a cause of crime: The cornerstone of forensic psychiatry. International Journal of Law and Psychiatry, 32(6), 342-347.

Arseneault, Louise, Terrie Moffitt, Avshalom Caspi, Pamela Taylor, and Phil Silva. 2000. Mental disorders and violence in a total birth cohort: Results from the Dunedin study. Archives of General Psychiatry, 57(10), 979-986.

Björnsson, Gunnar and Karl Persson. 2012. The explanatory component of moral responsibility. Noûs, 46(2), 326-354.

Clark, Michael. 1997. The Sanctions of the Criminal Law. Proceedings of the Aristotelian Society, 97(1), 25-39.

Committee on the Convention on the Rights of Persons with Disabilities. 2014. General Comment No. 1: Article 12: Equal Recognition Before the Law. United Nations. https://documents-dds-ny.un.org/ doc/UNDOC/GEN/G14/031/ Accessed 2019-11-15.

Convention for the Protection of Human Rights and Dignity of the Human Being with regard to the Application of Biology and Medicine: European Convention on Human Rights and Biomedicine (ECHRB) (Oviedo, 4 April 1997). Strasbourg: Council of Europe. http://conventions.coe.int/Treaty/ en/Treaties/Html/164.htm Accessed 2019-12-12.

Council of Europe, Committee of Ministers (2004) Recommendation Rec (2004)10 of the Committee of Ministers to member states concerning the protection of the human rights and dignity of persons with mental disorder and its explanatory memorandum, 22 September 2004. https://www.coe.int/t/ dg3/healthbioethic/Activities/08_Psychiatry_and_human_rights_en/Rec(2004)10\%20EM\%20E.pdf Accessed 2019-11-15.

Crocker, Anne, Tonia Nicholls, Michael Seto, Yanick Charette, Gilles Côté and Malijai Caulet. 2015. The national trajectory project of individuals found not criminally responsible on account of mental disorder in Canada. Part 2: The people behind the label. Canadian Journal of Psychiatry/Revue Canadienne de Psychiatrie, 60(3): 106-116.

Dahlin, Moa, Clara Gumpert, Marie Torstensson-Levander, Lupita Svensson and Susanna Radovic. 2009. Mentally disordered criminal offenders: Legal and criminological perspectives. International Journal of Law and Psychiatry, 32(6): 377-382.

Dawson, John and George Szmukler. 2006. Fusion of mental health and incapacity legislation. British Journal of Psychiatry, 188: 504-509.

Department of Health. 2005. Mental capacity act. London: Stationery Office http://www.legislation.gov. uk/ukpga/2005/9/pdfs/ukpga_20050009_en.pdf Accessed 2019-11-15.

Department of Public Safety and Emergency Preparedness. 2009. The investigation, prosecution and correctional management of high-risk offenders: A national guide https://www.publicsafety.gc.ca/cnt/ rsrcs/pblctns/2009-pcmg/2009-pcmg-eng.pdf. Accessed 2019-11-18. 
Douglas, Thomas. 2019. Is preventive detention morally worse than quarantine? In Predictive sentencing: Normative and empirical perspectives. Eds. Jan de Keijser, Julian Roberts and Jesper Ryberg. 69-88. Oxford: Hart publishing

Doyal Len and Julian Sheather. 2005. Mental health legislation should respect decision making capacity. BMJ, 331: 1467 doi: https://doi-org.ezproxy.ub.gu.se/https://doi.org/10.1136/bmj.331.7530.1467

Dressing, Harald and Hans Salize. 2004. Compulsory admission of mentally ill patients in European Union Member States. Social Psychiatry and Psychiatric Epidemiology, 39(10): 797-803.

Duff, Antony. 2001. Punishment, communication, and community. Oxford: Oxford University Press.

Duus-Otterström, Göran. 2007. Punishment and Personal Responsibility. Gothenburg: University of Gothenburg

Dworkin, Ronald. 2000. Sovereign virtue: the theory and practice of equality. Cambridge, Mass.: Harvard University Press.

Dåderman, Anna-Maria and Lars Lidberg. 1999. Flunitrazepam (Rohypnol) abuse in combination with alcohol causes premeditated, grievous violence in male juvenile offenders. Journal of the American Academy of Psychiatry and the Law, 27(1): 83-99.

Dåderman, Anna-Maria, Björn Fredriksson, Marianne Kristiansson, Lars-Håkan Nilsson and Lars Lidberg. 2002. Violent behavior, impulsive decision-making, and anterograde amnesia while intoxicated with Flunitrazepam and alcohol or other drugs: A case study in forensic psychiatric patients. Journal of The American Academy Of Psychiatry And The Law, 30(2): 238-251.

Elbogen, Eric and Sally Johnson. 2009. The intricate link between violence and mental disorder: Results from the national epidemiologic survey on alcohol and related conditions. Archives of General Psychiatry, 66(2): 152-161.

European Agency for Fundamental Rights (FRA). 2012. Involuntary placement and involuntary treatment of persons with mental health problems. Luxembourg: Publications Office. https://fra.europa. $\mathrm{eu} /$ sites/default/files/involuntary-placement-and-involuntary-treatment-of-persons-with-mentalhealth-problems_en.pdf Accessed 2019-11-14.

Fazel, Seena, Paul Lichtenstein, Martin Grann, Guy Goodwin and Niklas Långström. 2010. Bipolar disorder and violent crime: New evidence from population-based longitudinal studies and systematic review. Archives of General Psychiatry, 67(9): 931-938.

Fazel, Seena, Niklas Långström, Anders Hjern, Martin Grann and Paul Lichtenstein. 2009. Schizophrenia, substance abuse, and violent crime. JAMA, 301(19): 2016-2023.

German Criminal Code (1998). Version promulgated on 13 November 1998, Federal Law Gazette [Bundesgesetzblatt] I p. 3322, last amended by Article 1 of the Law of 24 September 2013, Federal Law Gazette I p. 3671 and with the text of Article 6(18) of the Law of 10 October 2013, Federal Law Gazette I p 3799. http://www.gesetze-im-internet.de/englisch_stgb/englisch_stgb.html?fbclid= IwAR2Btbzscjs1Yk2Ij9ueztYiK5QpDtpiAeixmv-BvcsSFhj6F2wbVtuZlaU\#StGBeng1_000P66 Accessed 2019-12-9.

Grisso, Thomas. and Appelbaum, Paul. 1998. Assessing competence to consent to treatment: A guide for physicians and other health professionals. New York: Oxford University Press.

Hart, Herbert. 2008. Punishment and Responsibility. Oxford University Press.

Juth, Niklas and Frank Lorentzon. 2010. The concept of free will and forensic psychiatry. International Journal of Law and Psychiatry, 33(1): 1-6.

King, Matt and Joshua May. 2018. Moral Responsibility and mental illness: A call for nuance. Neuroethics, 11(1): 11-22.

Kois, Lauren and Preeti Chauhan. 2018. Criminal responsibility: Meta-analysis and study space. Behavioral Sciences \& the Law, 36(3): 276-302.

Law Commission. 2013. Criminal Liability: Insanity and Automatism: A Discussion Paper. http://www. lawcom.gov.uk/app/uploads/2015/06/insanity_discussion.pdf Accessed 2019-12-09.

Mackay, Ronnie. 2012. Ten more years of the insanity defence. Criminal Law Review. (12): 946-954.

Mackay, Ronnie and Gerry Kearns. 1999. More Fact(s) about the Insanity Defence. The Criminal Law Review, (sep): 714-725

Mackay, Ronnie, Barry Mitchell and Leonie Howe. 2006. Yet More Facts about the Insanity Defence. The Criminal Law Review. (May): 399-411.

Mandarelli, Gabriele, Lorenzo Tarsitani, Giovanna Parmigiani, Gian Polselli, Paola Frati, Massimo Biondi and Stefano Ferracuti. 2014. Mental capacity in patients involuntarily or voluntarily receiving psychiatric treatment for an acute mental disorder. Journal of Forensic Sciences, 59(4): 1002-1007. 
Martin, Wayne, Sabine Michalowski, Timo Jutten, Matthew Burch. 2014. Achieving CRPD Compliance. Essex Autonomy Project: https://autonomy.essex.ac.uk/wp-content/uploads/2017/01/EAP-PositionPaper-FINAL.pdf Accessed 2019-11-20.

M'Naghten, R v. (1843) 8 ER 718 10; Cl \& F 200, 210 (M'Naghten's case) (House of Lords).

Mitchell, E.W. 2003. Self-Made Madness: Rethinking Illness and Criminal Responsibility. London: Routledge.

Model Penal Code. 1985. Official draft and explanatory notes: Complete text as adopted May 24, 1962. Philadelphia: American Law Institute.

Nilsson, Thomas, Christian Munthe, Christina Gustavson, Anders Forsman and Henrik Anckarsäter. 2009. The precarious practice of forensic psychiatric risk assessments. International Journal of Law and Psychiatry, 32(6): 400-407.

Owen, Gareth, Anthony David, Genevra Richardson, George Szmukler, Peter Hayward and Matthew Hotopf. 2008. Mental capacity, diagnosis and insight. Psychological Medicine, 22: 1-22.

Owen, Gareth, George Szmukler, Genevra Richardson, Anthony David, Vanessa Raymont, Fabian Freyenhagen, Wayne Martin and Matthew Hotopf. 2013. Decision-making capacity for treatment in psychiatric and medical in-patients: Cross-sectional, comparative study. The British Journal of Psychiatry, 203(6): 461-467.

Rawls, John. 1955. Two Concepts of Rules. The Philosophical Review, 64(1): 3-32.

Richardson, Genevra. 2002. Autonomy, guardianship and mental disorder: One problem, two solutions. Modern Law Review, 65(5): 702-723.

SBU (Statens beredning för medicinsk utvärdering) (Swedish Council on Technology Assessment in Health Care) 2005. Riskbedömningar inom psykiatrin - kan våld i samhället förutsägas? En systematisk litteraturgenomgång. (Risk assessments in psychiatry - can violence in society be predicted? A systematic literature review) Stockholm: Statens beredning för medicinsk utvärdering SBU.

Simon, Rita and Heather Ahn-Redding. 2008. Insanity defense the world over. Lanham, MD: Lexington Books.

Sjöstrand, Manne and Gert Helgesson. 2008. Coercive treatment and autonomy in psychiatry. Bioethics, 22(2): 113-120.

Singh, Jay, Martin Grann and Seena Fazel. 2011. A comparative study of violence risk assessment tools: A systematic review and metaregression analysis of 68 studies involving 25,980 participants. Clinical Psychology Review 31(3): 499-513.

Sinnott-Armstrong, Walter and Ken Levy. 2011. Insanity defenses. In The Oxford Handbook of Philosophy of Criminal Law. Eds. John Deigh and David Dolinko. 299-334. Oxford University Press.

Steadman, Henry, Edward Mulvey, John Monahan, Pamela Robbins, Paul Appelbaum, Thomas Grisso, Loren Roth and Eric Silver. 1998. Violence by people discharged from acute psychiatric inpatient facilities and by others in the same neighborhoods. Archives of General Psychiatry, 55(5): 393-401.

Straffeloven. 1902. Almindelig borgerlig Straffelov (Straffeloven). https://lovdata.no/lov/1902-05-22-10 Accessed 2019-11-18.

Swanson, Jeffrey, Charles Holzer, Vijay Ganju and Robert Tsutomu. 1990. Violence and psychiatric disorder in the community: Evidence from the epidemiologic catchment area surveys. Hospital and Community Psychiatry, 41: 761-770.

Szmukler, George, Rowena Daw and John Dawson. 2010. A model law fusing incapacity and mental health legislation. Journal of Mental Health Law, 20: 11-24.

Szmukler, George and Frank Holloway. 2000. Reform of the mental health act: Health or safety? The British Journal of Psychiatry, 177(3): 196-200.

Szmukler, George. 2017. Men in white coats: Treatment under coercion. Oxford: Oxford University press.

Tadros, Victor. 2011. The ends of harm: The moral foundations of criminal law. Oxford: Oxford University Press.

Tännsjö, Torbjörn. 1999. Coercive care: The ethics of choice in health and medicine. London: Routledge.

Walen, Alec. 2014. Retributive Justice. In The Stanford Encyclopedia of Philosophy (Winter 2016 Edition). Ed. Edward Zalta https://plato.stanford.edu/archives/win2016/entries/justice-retributive Accessed 2019-10-12.

World Psychiatric Association (WPA). 1983. The Declaration of Hawaii https://www.wpanet.org/decla ration-of-hawaii-ii Accessed 2021-06-04. 
Publisher's Note Springer Nature remains neutral with regard to jurisdictional claims in published maps and institutional affiliations. 